\title{
The Study of Hydraulic Brake for The High-Speed Train
}

\author{
Thi hoai thu $\mathrm{Vu}^{1,2, a}$, Jin chun Song ${ }^{2, b}$ \\ ${ }^{1}$ Transport and communication University, Viet Nam \\ ${ }^{2}$ School of Mechanical Engineering \& Automation, Northeastern University, Liaoning Shenyang, \\ China \\ a 1744648501@qq.com; ${ }^{b}$ jchsong@mail.neu.edu.cn;
}

Keywords: Brake technology; Hydraulic brake; MATLAP/Simulink ; The test bench of Electro Hydraulic braking system

Abstract: During the process of improving train speed, carry capacity and quantity of cars for each train, the most technical challenging task for an engineer is dealing with the braking system. Besides using common braking technologies such as electric brakes, air brakes and eddy current brakes, we need to study and apply advanced braking technologies such as the hydraulic brake or the wing plate brake... Set up a high-speed train electro-hydraulic brake system model, and then use MATLAP/Simulink- to simulate the actual future use to provide a theoretical basis and ensure the safety operation of high-speed train. Construction of the test bench of electro -hyraclic braking system for high -speed train.

\section{Introduction}

The development of high-speed train is fast, in many countries, the speed of train has reached $350 \mathrm{~km} / \mathrm{h}$. Increasing train speed need to go along with the improvement of the safety. Brake technologies play an important role on the safety of the train operation. To avoid accident, the shorter of braking distance is better. It is essential to have deep research on new braking methods when developing high speed trains. Traditional brake systems don't have enough capacity to ensure quick, accurate and synchronized braking requirements. Thus, development of new braking system with high reliability and light weight is a key requirement.

The advantages of hydraulic brake system is the compact size, low cost, easy to set in automatic controlled and link with other parts of the train. The system working with high reliability and require less maintenance, it can be used in high speed and collision proof. This article will mainly introduce the principle and components of a hydraulic brake sysem.

\section{Hydraulic Braking System}

Hydraulic brake system uses a piston-cylinder structure and leverage to transmit the force of the hydraulic cylinder brake into the brake disc. The principle is often used by oil pressure driven piston motion transmission, transmission shift piston to tension brake system brake shoe soles applied to squeeze the brake shoe causing the disc brake stopping power cause arises. 


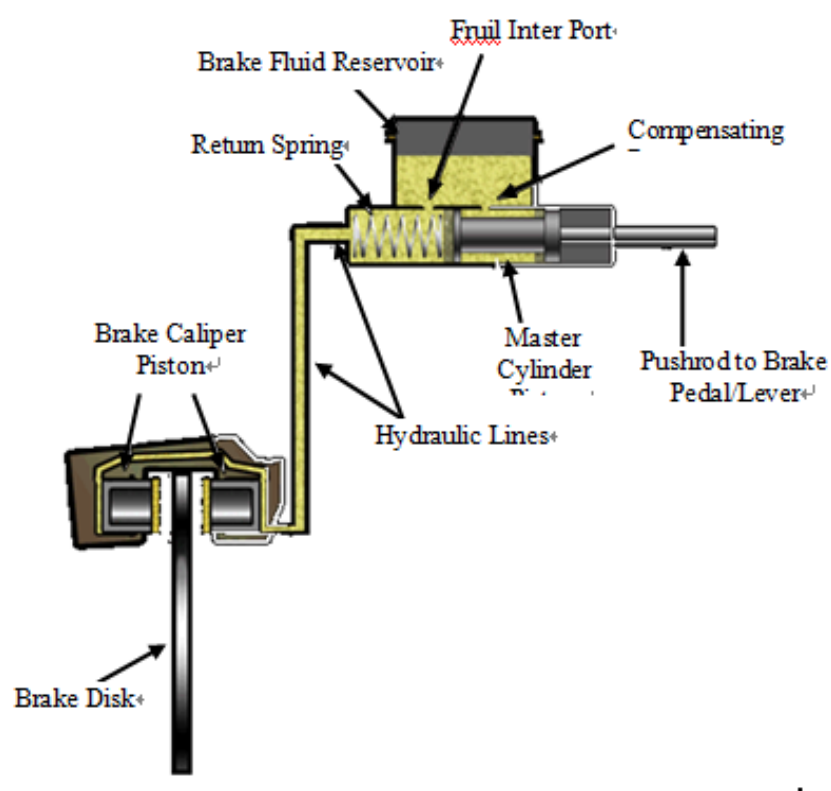

Fig 1: Diagram Hydraulic brake system

\subsection{Hydraulic braking system used on high-speed trains}

Schematic diagram of hydraulic system is shown in figure 2. The hydraulic braking system according to functional points can be divided into 3 groups: Microcomputer Brake Controller Unit (MBCU), Electro Hydraulic Braking Equipment and Basic Braking Equipment. MBCU receives services braking instruction, emergency braking instruction, electro-pneumatic brake feedback, ATC signal etc, input then after computer processing, giving output of service braking commands.

\subsection{Effect of the system}

A. Brake control: When implementing the brake, the first braking electromagnetic valve is powered on preparing brake. Braking command signal goes through the brake electronic control unit, after calculation and conversion into the amplifier of PPRV input control signal, the electronic amplifier pressure reducing valve electromagnetic force corresponds, so the outlet signal pressure of PPRV and input signal of electronic amplifier is proportional to the value. Oil pressure energy storage is released through the filter, service brake electromagnet valve, PPRV, throttle valve, shuttle valve, pipe explosion prevention valve, into the brakes, braking vehicle. When release brake, brake electromagnet valve power loss, pressure oil come back to tank, release brake.

B. Emergency brake control

It is similar to braking control; while implementing the emergency brake, emergency electromagnet brake power on. 


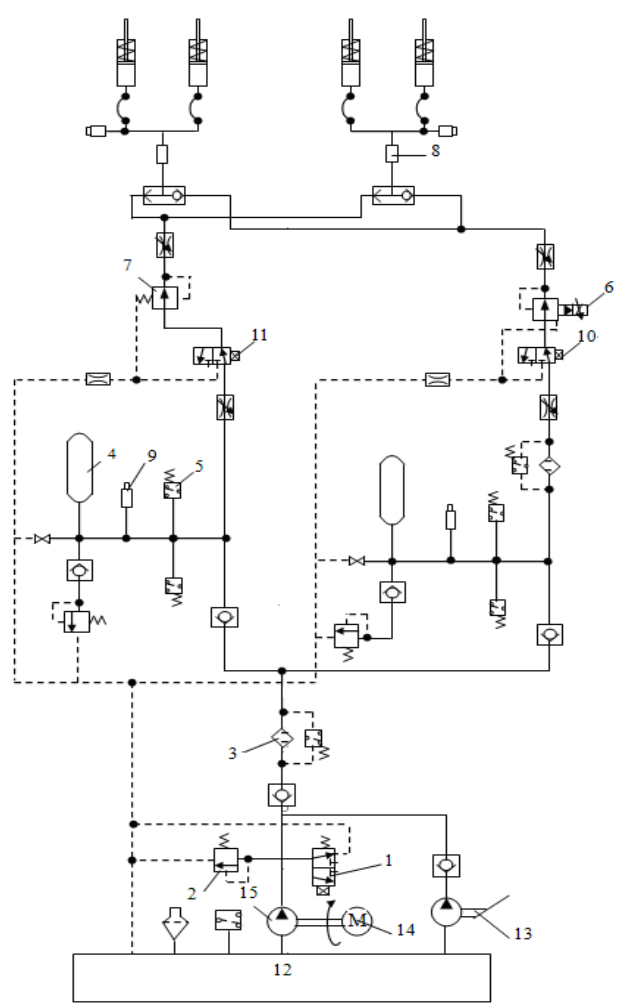

Fig. 2: Diagram Hydraulic brake system used on high-speed trains

1.Unloading valve; 2. Overflow valve; 3. Filter; 4. The energy storage; 5. Pressure relay; 6.Proportional pressure reducing valve (PPRV); 7. Pressure relief valve; 8.Pipeline explosion prevention valve;9. Pressure sensor; 10. Braking valve; 11 . Emergency brake valve; 12 . Tank oil;

13. Pump hand; 14. Motors; 15. Hydraulic Pump

\section{$\vdots$}

\subsection{Simulation electro-hydraulic brake system of high-speed train}

(1) Electro hydraulic proportional valve

The electro-hydraulic proportional valve adopts a straight moving type three way proportional pressure reducing valve.

A.The force balance equation

Ignore the hydraulic clamping force, by theorem of the motion of Newton, acting on the control valve on the force balance equation:

$$
F-p_{L} A_{1}=m \frac{d^{2} x}{d t^{2}}+B_{1} \frac{d x}{d t}+K_{1}\left(x_{0}+x\right)
$$

With: $\quad p_{L^{-}}$brake pressure, Pa; $A_{1}$ - Pressure detecting piston area, $\mathrm{m}^{2} ; \mathrm{m}$ - Quality components, valve core and the equivalent kg; $B_{1}$-Comprehensive damping coefficient, N.s $/ \mathrm{m} ; K_{1}$ Valve on the spring stiffness, $\mathrm{N} / \mathrm{m} ; x_{O}$ - The spring pre compression, $\mathrm{m} ; x$-Spool displacement, $\mathrm{m}$.

B. Three way valve flow rat equation

$$
d q_{L}=\frac{\partial q_{L}}{\partial x} \Delta x+\frac{\partial q_{L}}{\partial p_{L}} \Delta p_{L}=K_{q} \Delta x-K_{c} \Delta p_{L}
$$

With: $K q$ - Flow gain; $K$ - Flow pressure coefficient

(2) Brake actuator modeling

A. Brake piston force balance equation

The movement of the piston can be divided into two stages. Give $y$ - Brake piston displacement and $y_{\max }$-the gap between brake caliper and brake discs

The first stage: $y<y_{\max }$ :

$$
p_{C} \cdot A_{2}=M \frac{d^{2} y}{d t^{2}}+B_{2} \frac{d y}{d t}+K_{2}\left(y_{0}+y\right)
$$


With: $M$ - Brake piston and its accessories quality; $B_{2}$-Viscous friction coefficient between brake piston and cylinder; $K_{2}$ - Brake return spring stiffness; $y_{o}$ - Brake return spring of initial amount of compression; $p_{C}$ - Hydraulic cylinder oil; $A_{2}$ - Brake piston area.

The second stage $y=y_{\max }$ :

$$
p_{L} \cdot A_{2}=K_{2}\left(y_{0}+y_{\text {max }}\right)+F_{L}
$$

B. Brake flow equation

$$
q_{C}=A_{2} \frac{d y}{d t}+C \cdot p_{L}+\frac{V_{t}}{4 \beta} \cdot \frac{d p_{L}}{d t}
$$

With: $\beta$ - Oil elastic modulus hydraulic;

$q_{C}$ - Brake cylinder flow;

$C$ - Leakage coefficient;

$V t$ - Total compressed volume

According to the above analysis chart control model of brake pressure of Maltap/Simulink as shown in figure 3 .

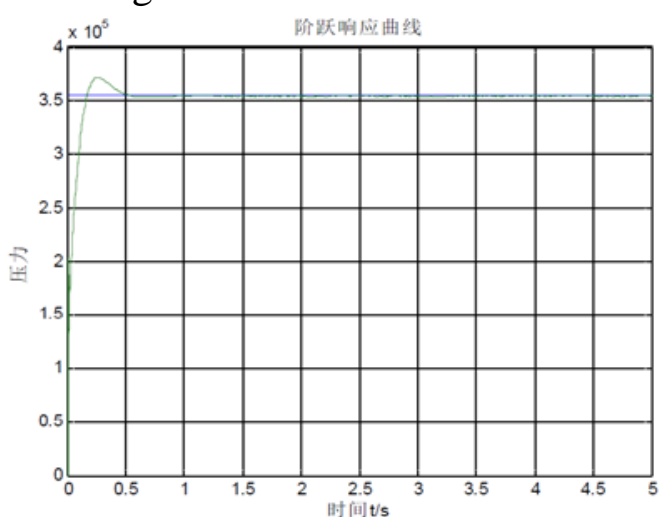

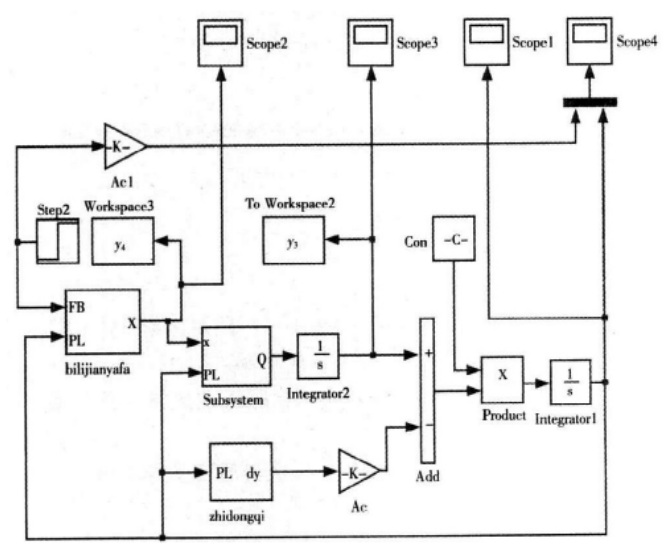

Fig.3 The brake pressure control model diagram

Table 1 The performance of PID control system

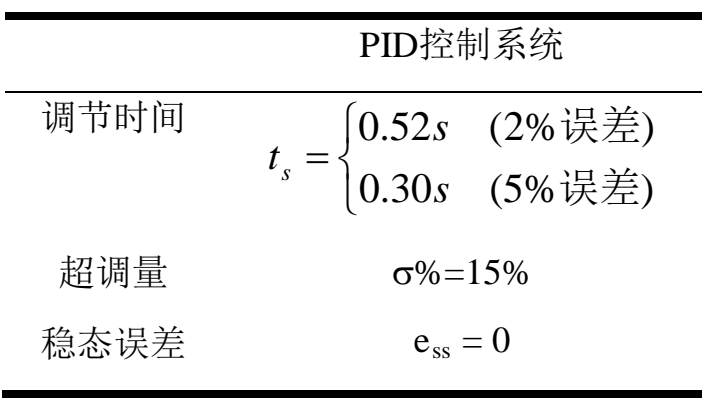

Fig.4 The PID correction system sinusoidal response

\section{Construction the test bench of electro-hydraulic braking system for high-speed train}

The braking simulation principle of the train braking test bench is shown in figure 5. The output of the hydraulic pump driven by the motor is driven by the hydraulic oil. In pressing oil cylinder branch, hydraulic oil through the valve to a three position four-way electromagnetic reversing valve, through the control valve to the liquid control one-way valve, before the arrival of the pressing cylinder, when a three position four-way electromagnetic valve YV2, reversing valve right through, cylinder rod into the oil chamber, hydraulic brake in braking state, when digital pressure reaches the braking pressure, can let YV2 loss of power, brake maintain braking; braking to stop, a three position four-way reversing valve YV2 electricity, pressing oil cylinder without rod chamber into the oil, brake exit braking state. At the same time, in the spindle motor branch, hydraulic oil through the two position four-way electromagnetic reversing valve, flow through the one-way throttle valve, arrive at the rotation shaft of the motor, the spindle motor rotation, drive shaft rotation, one-way throttle valve to control the flow, in order to control the speed of the motor shaft, so as to simulation of train axle rotating at different speeds. 


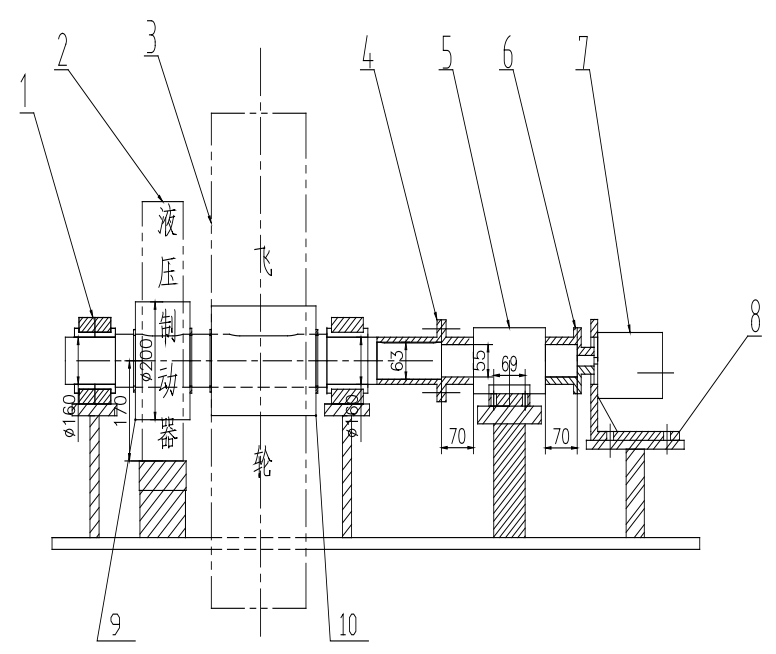

Fig 6 Schematic diagram of mechanical system structure of test bed

1.Sliding bearing; 2.Hydraulic brake; 3.Inertia fly wheel;4, 6.Coupling; 5.Tougue meter; 7.Motor; 8.Motor support; 9.Hydraulic brake bushing; 10. Fly wheel bushing

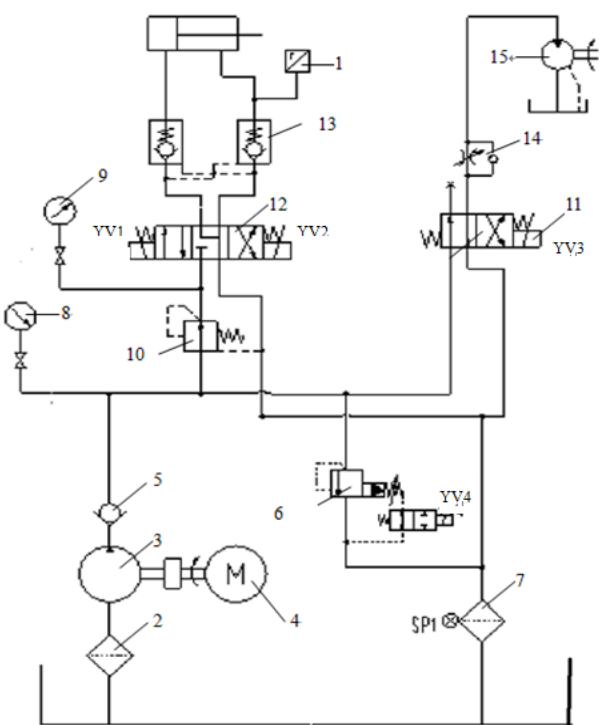

Fig.5 The schematic diagram test bench of hydraulic braking

1. Digital pressure; 2. Oil filter; 3. Vane pump; 4. Motor; 5. One-way valve; 6.Electromagnetic relief valve; 7.Return oil filter; 8, 9. Vibration proof pressure gauge; 10.Superposition valve; 11, 12.The electromagnetic directional valve; 13 .

Double liquid control one-way valve; 14 . Superposition type one-way throttle valve; 15 . Gear motor;

The test bench is a complicated control system, which can simulate the braking condition of the train. The test rig is designed and developed based on the electro pneumatic braking system and hydraulic brake. According to the design requirements of hydraulic brake test system, the system mainly includes three parts:

(1) Hydraulic system includes all kinds of hydraulic valves, piping system, oil tank, a motor, an oil pump, etc. used for adjusting the hydraulic pressure system. The dynamic pressure in the hydraulic cylinder, spindle speed. Simulation of brake pressure in the braking process.

(2) The mechanical system is composed of motor, coupling, inertial flywheel group system, each bracket, braking device, testing device and so on. It simulates the train wheel rotation, and brake shoe, brake process. (Figure 6)

(3) Measurement and data acquisition system is mainly of braking force, spindle speed (that is, wheel speed, hydraulic brake cylinder pressure test data were measured through the sensor, hydraulic table, followed by data collection processing equipment, the data will be transmitted to the computer, computer processing, obtained with the display results and parameters.

\section{Conclusions}

This paper introduces a new design is hydraulic brake system, and gives a brief introduction of the working principle of the hydraulic system design . Use Matlab/Simulink simulation. Can be seen from Fig4 and table 1, the overshoot of the system and the response time is possible.

Construction the test bench of electro-hyraulic braking system for high speed train.

\section{References}

[1]. LI He-ping, LIN Hu- ting. A study desigh of high- speed basic braking system [J]. China railway Science 2003,24(2):8-13.

[2]. SONG Jin-chun. Hydraulic Technology and Practical Handbook [M] . China Electric Power Press, 2010.

[3]. XUE Ding-yu, CHEN Yang -quan. MATLAB higher applied mathematics problem solving [M], Beijing: Tsinghua University Press). 